\title{
Orthodontic treatment of an unerupted mandibular canine tooth in a patient with mixed dentition: a case report
}

\author{
Maria Teresa Dinoi ${ }^{1 *}$, Enrico Marchetti ${ }^{1}$, Umberto Garagiola² ${ }^{2}$ Silvia Caruso ${ }^{1}$, Stefano Mummolo ${ }^{1}$ \\ and Giuseppe Marzo'
}

\begin{abstract}
Background: The aim of this case report was to describe the surgical-orthodontic treatment of an unerupted mandibular canine tooth in a 9-year-old girl.
\end{abstract}

Case presentation: A 9-year-old white girl presented with an unerupted right mandibular canine tooth. Combined surgical-orthodontic treatment was performed to correct dental impaction and to achieve good aesthetic and functional results.

Conclusion: Orthodontic treatment achieved all of the required objectives.

Keywords: Unerupted, Orthodontics, Canine tooth, Mixed dentition

\section{Background}

Dental eruption is a dynamic and complex biological and physiological process that occurs over several years. The process includes the formation of teeth and their migration in the jaws until their eruption in their final functional position in the dental arches. The age at which the temporary and permanent teeth appear varies markedly among individuals and can be related to several factors, including gender, dentition, socioeconomic status, and height.

Under certain anatomical conditions, trauma or infective processes involving the deciduous teeth can cause alterations of their eruptive process, preventing the permanent tooth from appearing in the oral cavity within the physiological eruption timeframe or causing ectopic positioning. A tooth is considered "impacted" when it fails to erupt in the dental arch within the expected developmental window. Teeth may become impacted because of adjacent teeth, dense overlying bone, excessive soft tissue, or genetic abnormalities. The reported incidence of dental impaction varies between 5.6 and $18.8 \%$, with a higher frequency among women [1].

\footnotetext{
* Correspondence: teresadinoi@hotmail.it

${ }^{1}$ Department MeSVA, School of Dentistry, University of L'Aquila, L'Aquila, Italy Full list of author information is available at the end of the article
}

The third molars are most frequently impacted (20 to 30 $\%)$ because they are the last teeth to erupt in the oral cavity, followed by the maxillary canines ( $85 \%$ with palatal dislocation), mandibular second premolars $(0.3 \%)$, and central maxillary incisors $(0.1 \%)$ [2-5].

Several classifications can be used to evaluate the degree of tooth impaction. These classifications are based on different factors, such as duration of impaction (that is, temporary versus permanent), number of impacted teeth (that is, single versus multiple) [6], the degree of impaction (that is, total versus partial) [6], and cause of impaction (that is, primary versus secondary). Primary impaction is caused by intrinsic factors, such as tooth anatomy and tilt, whereas secondary impaction is caused by external factors, such as cystic lesions, supernumerary teeth, and neoplasms [6].

The etiopathogenesis of dental impaction is vast. Causes of dental impaction can be classified as general, local, structural, and systemic. General causes include genetics, endocrine hypofunction or hyperfunction, metabolic dysfunction, and infectious diseases [7]. Local causes include obstructed eruption, lack of space, ankylosis of primary or permanent teeth, ectopic position of the tooth bud, dilacerations of the roots, soft tissue or bony lesions, fibrosis, and habits [7]. Structural causes 
include maxillary hypoplasia, severe hyperdivergence, skeletal open bite, and congenital pathologies of the maxillofacial system [7]. Systemic factors include prenatal causes (heredity), postnatal tuberculosis, anemia, malnutrition, and endocrine disorders of the thyroid or parathyroid gland.

Several therapies are possible for impacted teeth, including classic orthodontic treatment, combined surgical-orthodontic treatment, conservative surgery, and radical surgical treatment [7]. In the simplest cases of tooth retention, conventional orthodontic treatment should be chosen. When the impacted tooth has anomalies of location and inclination or a particular coronoradicular morphology, combined surgical-orthodontic treatment should be chosen. When tooth eruption is hampered by a pathological condition, such as a cyst or odontoma, and the tooth's position in the arch depends on removal of the obstacle, conservative surgical treatment should be selected. In the case of serious anomalies in tooth anatomy or location, or at the patient's request, radical surgical treatment (extraction) may be chosen. Maintaining the teeth in the arch is important, to ensure that the patient will have adequate functionality and good aesthetics.

\section{Case presentation}

This case report describes the case of a 9-year-old white girl with mixed dentition. An extraoral examination revealed no significant facial asymmetry. An intraoral examination showed dentition appropriate for her age (Fig. 1). She had no family or medical history that would explain eruption abnormalities.

Orthopantomography of her dental arches and a lateral teleradiograph of her cranium were performed for cephalometric evaluation to allow planning of an appropriate treatment plan. Orthopantomography showed an unerupted right canine tooth. As shown in Fig. 2, the

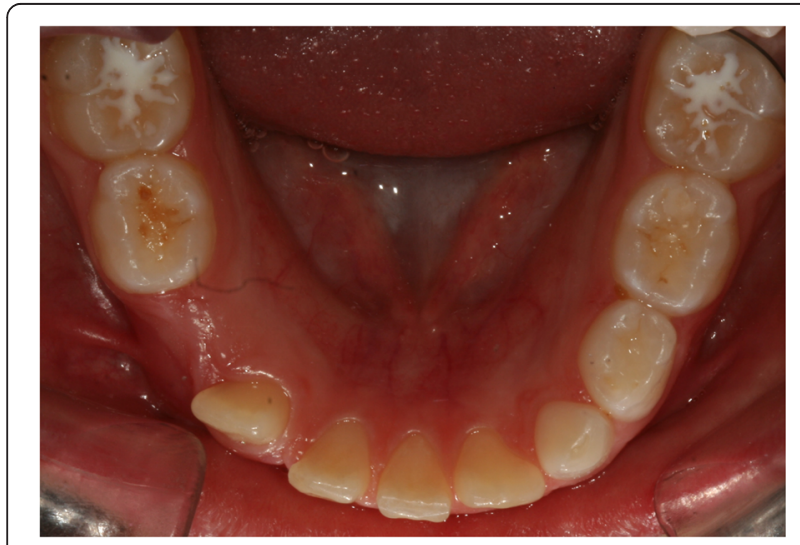

Fig. 1 Initial intraoral photograph of the mandible

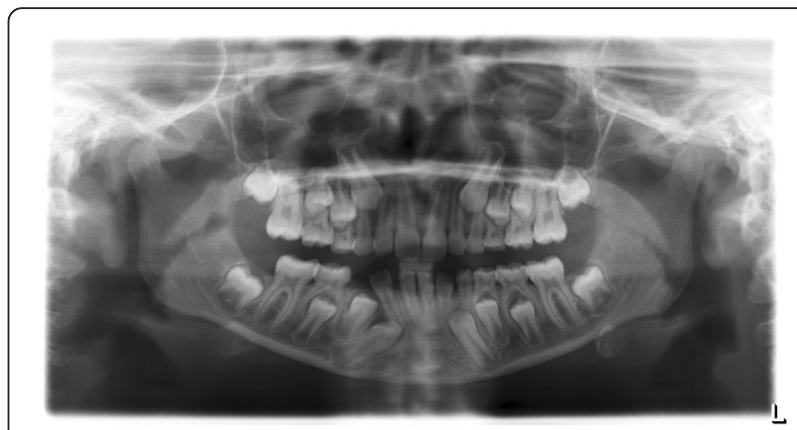

Fig. 2 Initial panoramic radiograph

canine tooth still had eruptive capacity but no physiological eruptive path was present.

At her age, functional treatment is generally advisable. However, considering the canine ectopia, surgicalorthodontic treatment was chosen to move the canine into her arch. This case shows that it is important to act early, during the mixed dentition phase, to prevent worsening impaction of ectopic teeth, which could require tooth extraction at a later stage. The treatment involved creating a surgical incision next to her unerupted canine, applying traction on the tooth toward her arch with an anchoring device and bonding of her lower arch,
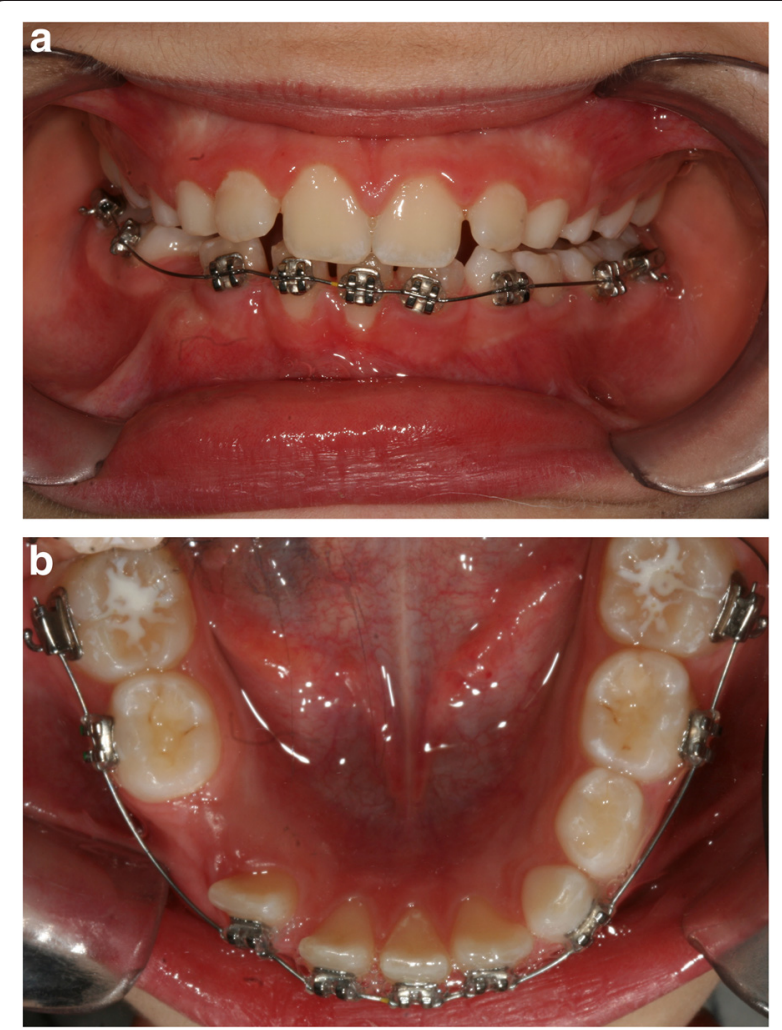

Fig. 3 a b Banding of the lower arch 


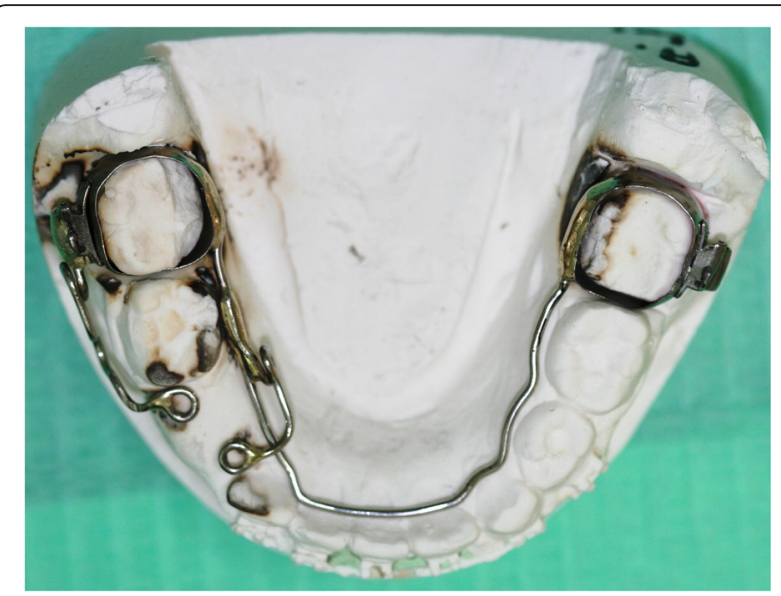

Fig. 4 Lingual arch

followed by a phase of functional orthodontics to improve the shape of her arches.

The first session involved bonding her lower arch with prepressed and pre-angled attachments to align the four incisors. The first archwire used was 0.014-inches $(0.356$ $\mathrm{mm}$ ) round archwire made of nickel and titanium. Bonding was performed using her primary teeth to provide a greater anchor (Fig. 3a, b).

In the next session, we replaced the round archwire with $0.016 \times 0.022$-inches $(0.406 \times 0.559 \mathrm{~mm})$ rectangular archwire made of nickel and titanium. A dental impression was made with the orthodontic bands on her mandibular sixth tooth to build a mandibular lingual archwire than eyelet in area 43 , which was necessary to apply traction to her impacted tooth (Fig. 4).

Twenty days later a surgical opening was made (Fig. 5). A button was placed at the coronal level of her unerupted tooth and was tied with elastic thread to the eyelet of the auxiliary appliance to provide traction. The lingual archwire was cemented after the surgical opening.

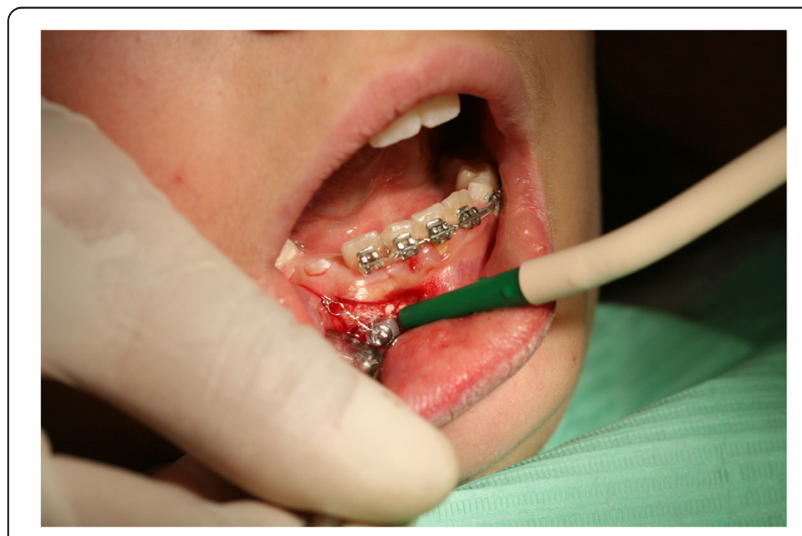

Fig. 5 Surgical opening

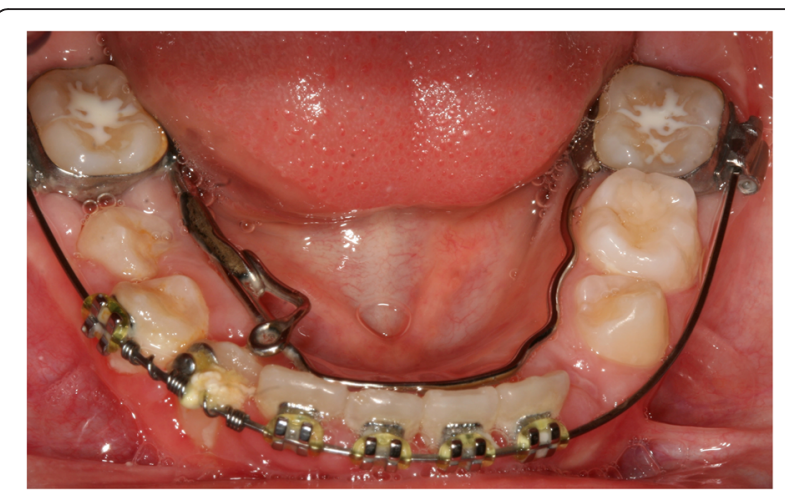

Fig. 6 Canine tooth visible in the arch

Traction was applied slowly, with replacement of the elastic thread every 15 days. Approximately 4 months after the surgical opening was made, the tooth became visible in her arch (Fig. 6). Traction on the tooth continued to guide it to its physiological seat. The button was replaced with a prepressed and pre-angled attachment.

Approximately 8 months after surgery, the tooth had moved to its physiological location and the bands were removed from her lower arch (Fig. 7a and b).

Orthodontic treatment (Fig. 8) was continued with two Schwarz appliances to slowly expand her arches and to improve their shape, postponing the final alignment of her teeth to a later stage, when her dentition will be complete.
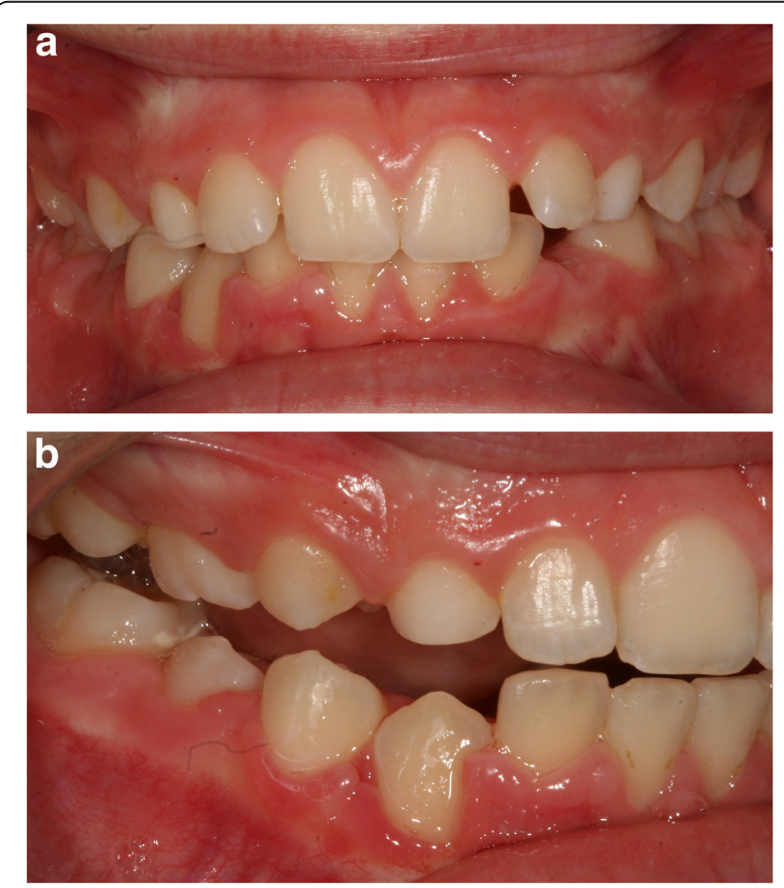

Fig. 7 a Front final photographs, b Lateral final photograph 


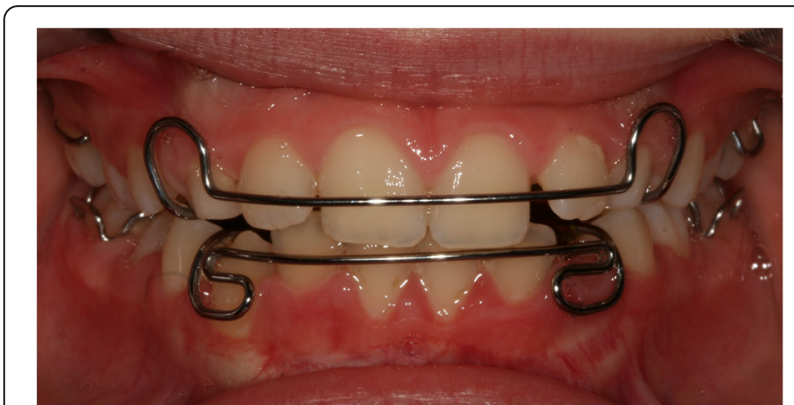

Fig. 8 Schwarz retainers
5. Dinoi MT, Lacarbonara M, Dimartino S, Monaco A, Marzo G. Periodontal probing of a impacted tooth recovered through a surgical-orthodontic approach: a case report. J Med Case Rep. 2014. doi:10.1186/1752-1947-8-25.

6. Valletta G, Matarasso S, Mignogna M. Malattie Odontostomatologiche. Piccin; 2005

7. Annibali S, Pippi R, Sfasciotti GL. Chirurgia orale a scopo ortodontico. Masson; 2007

\section{Conclusions}

The purpose of this case report was to describe the combined surgical-orthodontic treatment of an unerupted mandibular canine tooth in a 9-year-old girl. Given her age, functional treatment would generally be advisable to expand her arches. In this case we preferred to immediately implement fixed treatment to bring the canine into her arch and to avoid the risk of the tooth requiring extraction with delayed treatment. The treatment was successful, with recovery of the impacted canine. Good aesthetic and functional results were achieved.

\section{Authors' contributions}

MTD conceived of the study, participated in its design and coordination, and helped to draft the manuscript. EM conceived of the study, participated in its design and coordination, and helped to draft the manuscript. SM conceived of the study, participated in its design and coordination, and helped to draft the manuscript. SC conceived of the study, participated in its design and coordination, and helped to draft the manuscript. GM and UG conceived of the study, participated in its design and coordination, and helped to draft the manuscript. All authors read and approved the final manuscript.

\section{Competing interests}

The authors declare that they have no competing interests.

\section{Consent}

Written informed consent was obtained from the patient's legal guardian for publication of this case report and any accompanying images. A copy of the written consent is available for review by the Editor-in-Chief of this journal.

\section{Author details}

'Department MeSVA, School of Dentistry, University of L'Aquila, L'Aquila, Italy. ${ }^{2}$ Biomedical Surgical and Dental Sciences Department, University of Milan, Milan, Italy.

Received: 31 March 2015 Accepted: 3 May 2016

Published online: 10 June 2016

\section{References}

1. Frank CA. Treatment options for impacted teeth. J Am Dent Assoc. 2000; 131(5):623-32

2. Chiapasco M, Crescentini P, Garattini G, Meazzini MC. Manuale illustrato di Chirurgia Orale. 2005.

3. Gyulai-Gaal S, Mihalyi S, Martonffy K, Suba Z. Etiology and diagnostic of upper canine tooth retention. Fogorv Sz. 2010;103(2):49-52.

4. Olive RJ. Orthodontic treatment of palatally impacted maxillary canines. Aust Orthod J. 2002;18:64-70.
Submit your next manuscript to BioMed Central and we will help you at every step:

- We accept pre-submission inquiries

- Our selector tool helps you to find the most relevant journal

- We provide round the clock customer support

- Convenient online submission

- Thorough peer review

- Inclusion in PubMed and all major indexing services

- Maximum visibility for your research

Submit your manuscript at www.biomedcentral.com/submit
Ciomed Central 